Instructions for authors, subscriptions and further details:

\title{
¿Quién Teme al Espejo? Una Polémica Sociológica en Torno a Cómo los Gays Ven el Envejecimiento Gay
}

Ernesto Meccia ${ }^{1}$

1) Universidad Nacional del Litoral y Universidad de Buenos Aires, Argentina

Date of publication: January $30^{\text {th }}, 2016$

Edition period: January 2016 - July 2016

To cite this article: Meccia, E. (2016). ¿Quién Teme al Espejo? Una Polémica Sociológica en Torno a Cómo los Gays Ven el Envejecimiento Gay. Research on Ageing and Social Policy, 4(1), 70-95. doi: 10.17583/rasp.2016.1723

To link this article: http://doi.org/10.17583/rasp.2016.1723

\section{PLEASE SCROLL DOWN FOR ARTICLE}

The terms and conditions of use are related to the Open Journal System and

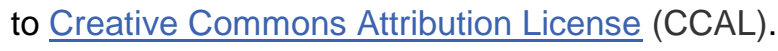




\section{¿Quién Teme al Espejo? Una Polémica Sociológica en Torno a Cómo los Gays Ven el Envejecimiento Gay}

Ernesto Meccia

Universidad Nacional del Litoral y Universidad de Buenos Aires

\section{Resumen}

Se analizan distintas formas de representación social del envejecimiento gay por parte de personas mayores gays. Se traen elementos de distintos enfoques teóricos: la teoría de la "competencia en crisis", teorías de "ajuste y resiliencia", la teoría del "envejecimiento acelerado" y la teoría del "estrés de minorías". La reflexión se ciñe al envejecimiento que experimentan personas gays que han vivenciado las grandes transformaciones sociales de la homosexualidad, discernibles en las sociedades occidentales a partir los años 70, asumiendo que los mismos representan una subjetividad gay "bisagra" que estaría conformada por repertorios representacionales contrastantes, unos provenientes de la antigua homosexualidad en la que se socializaron primariamente, y otros del modelo gay propiciado, genéricamente, luego de la revuelta de Stonewall. Desde el punto de vista metodológico, se transita cada una de las teorías intentado señalar sus aciertos y limitaciones, aportando datos primarios (entrevistas) y secundarios (estadísticas sobre percepciones y entrevistas). Como conclusión, se señala que se han observado situaciones contrastantes por identidad sexual, por ámbito de escenificación de la identidad (los de la salud médica se observan claramente regresivos) y por las características que los sujetos adjudican a los entornos institucionales dentro de los que desarrollaron su biografía.

Palabras clave: homosexualidad, envejecimiento, modelos perceptivos, marcos de la experiencia, otros significativos. 


\section{Who's Afraid of the Mirror? A Sociological Polemic on the Gay Vision of the Gay Ageing}

Ernesto Meccia

Universidad Nacional del Litoral y Universidad de Buenos Aires

\section{Abstract}

Our aim is to analyze different representational forms of gay ageing by old gays. We will draw on aspects related to various theoretical viewpoints and enhance them by presenting empirical evidence with a critical approach. Thus, we will delve into the theory of competence in crisis, some theories of adjustment and resilience, the theory of fast aging, and last, the theory of minority stress. Our reflection is focused on aging experienced by gays who have witnessed social changes as from the 70 s, taking into account they represent a turning point in gay subjectivity formed by contrasting representational repertoires, some deriving from an old homosexuality pattern in which they socialized primarily and others from the gay model fostered, generically, after the Stonewall uprising. From the methodological point of view, the texts of the authors considered representative of the theories mentioned are crossed. Then, each was busy trying to point out their particular strengths and limitations providing primary data (interviews) and secondary (statistics on perceptions and interviews). In conclusion, it is noted that there have been contrasting situations in the aging process based on heterogeneous analysis variables, including: sexual identity, the scene of identity (areas of healthcare are clearly regressive to show the gay identity) and, among others, by the features that subjects allocated to institutional environments within which developed his biography.

Keywords: homosexuality, ageing, perceptual models, experience frames, significant others. 


\section{Ernesto Meccia - Cómo los Gays Ven el Envejecimiento Gay}

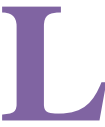

a problemática del envejecimiento gay presenta varias dimensiones analíticas: se lo puede abordar desde la sociología de la salud, de las generaciones, de las identidades, de la percepción, o desde modelos teóricos específicamente gerontológicos. Todos ellos aportan elementos para la discusión. Sin embargo, en este artículo no tomaremos ninguno de esos atajos. Antes bien, intentaremos utilizarlos para reconstruir una polémica en torno a las formas en que los varones gays en proceso de envejecimiento pueden representarse el envejecimiento gay.

Las percepciones de las personas y de los grupos sociales se construyen en clave relacional. Producto del carácter transversalmente dialógico de la percepción, las subjetividades ponen a existir "otros" (concretos o imaginados) a través de los cuales hacen inteligible la propia posición dentro de las cambiantes circunstancias de la vida social. Es pertinente, por lo tanto, prestar atención a quiénes harían presentes los gays cuando piensan su propio envejecimiento, es decir, cuáles serían los "otros significativos" (Mead, 1972; Goffman, 1974; Becker, 2009) que son puestos a funcionar como puntos de referencia. ¿La vejez legítima será solamente la vejez que disfrutan los heterosexuales? ¿O la que solamente pueden vivir los gays?

Que la edad es más una cuestión de percepción que de posesión, o que es más un estado de la subjetividad individual que expresa otro estado del alma colectiva y de la organización social, es una hipótesis que manejan los sociólogos de las generaciones. Por eso, estudiar el envejecimiento gay implica adoptar una perspectiva subjetiva y otra objetiva, lo cual equivale a reafirmar aquel principio de Pierre Bourdieu (2007) que expresa que lo social existe dos veces: en las psiquis y en las estructuras.

Los modos en que se ven a sí mismos los gays mayores requieren argumentos que incorporen el entramado estructural de la homosexualidad y sus transformaciones. De lo contrario no podría comprenderse por qué, "en privado", la gente gay se siente vieja antes de tiempo, o por qué logra sentirse vieja mucho después que sus pares heterosexuales, o por qué otros nunca llegan a sentirse así, más allá de que todas se hayan puesto a observar su cuerpo en la intimidad. Y es que gran parte de la verdad sobre quién le teme al espejo se encuentra afuera de nosotros. Lo que encontramos en el espejo es, sociológicamente considerada, nuestra corporeidad en tanto "ejemplo" de un modelo perceptivo que, de formas siempre reguladas aunque variadas, nos la hace ver de un modo característico. En otras 
palabras, lo que aparece en el "cuerpo gay" que envejece son las propiedades de un conjunto de convenciones que nos han interpelado y en las que nos hemos reconocido.

Esta argumentación es particularmente valedera para nuestros propósitos ya que vamos a considerar a los integrantes de una categoría social que hasta hace poco tiempo era unilateral y asimétricamente objeto de discursos homofóbicos. Por lo menos hasta la década del 70, la homosexualidad era "hablada" casi exclusivamente por los saberes médico, psiquiátrico, psicoanalítico y religioso, a los que es preciso sumar una discursividad de sentido común informal pero no por ello menos sistemática. Las acentuaciones monstruosas de las que era objeto lograban crear pánico ante la presencia o la cercanía de los "representantes" del arquetipo así construido y cotejado. También lograban crear auto pánico, una opresiva conciencia deletérea en los mismos gays que terminaban viviendo presos de la homofobia internalizada. Justamente, una de las acentuaciones negativas más extendidas y unilaterales respecto de la homosexualidad fue la vejez. Recórranse películas, cuentos y novelas o hagamos memoria de las leyendas de los barrios de las grandes ciudades y/o de los pequeños pueblos y allí aparecerá característicamente decadente y/o amenazante el "viejo" homosexual. ${ }^{1}$

Con posterioridad a los episodios de Stonewall (EEUU, 1969), se inaugurará un momento que tiene como característica más notable la puesta en circulación de discursos que expresan desde adentro el mundo gay. Son todos discursos de afirmación que parecieran responder una a una a las predicaciones monstruosas de la homofobia, la mayoría de las veces desmarcándose aunque otras reivindicando la "anormalidad". Así los discursos del "gay pride" y del "coming out" llegaron a ser narrativas transversales de la homosexualidad en las sociedades occidentales. Es de esperar, en estas condiciones, que el envejecimiento gay pueda comenzar a enmarcarse en otros modelos perceptivos, algo de lo que ya estarían dando cuenta algunas películas. ${ }^{2}$

Por lo tanto, más que preguntarnos por el envejecimiento gay queremos preguntarnos por los modelos perceptivos del mismo, o por los "marcos de la experiencia" (Goffman, 2006) en los cuales lo alojamos, o por las grillas interpretativas de la realidad gay de las que disponen los gays en momentos históricos determinados. 


\section{Ernesto Meccia-Cómo los Gays Ven el Envejecimiento Gay}

En nuestros días viven personas gays cuya subjetividad es producto de haber transitado distintas configuraciones societales de la homosexualidad: en un momento tuvieron "disponible, al alcance de la mano" (Schutz, 1974) un repertorio representacional marcadamente homofóbico (y nada más) y luego una variedad de repertorios derivados del gay pride. No solamente conocieron repertorios de ambos tipos, también conocieron configuraciones jurídicas distintas, entramados institucionales y de socialización contrastantes. Esas personas, hoy por hoy, son viejas o se encuentran transitando el proceso de envejecimiento. La pregunta ya puede imaginarse: ¿con qué modelos perceptivos lo verán y se verán? (Meccia, 2011).

Dijimos que a partir de la revuelta de Stonewall, en Estados Unidos, en 1969, lo gay comenzó a ser dicho en sus propios términos y se tradujo en movimiento político. 1969 representa, sin lugar a duda, un punto de giro. Cada país, llegado el momento, ha tenido "su" Stonewall. Pensemos en los gays estadounidenses que hoy tienen cerca de 90 años: en ocasión de Stonewall tenían 45; los que hoy tienen 80 tenían 35; los que tienen 70 tenían 25, y así sucesivamente. En mi país (Argentina) existe alto consenso en visualizar la reapertura democrática de 1983 (luego de la dictadura militar más luctuosa de la historia) como el inicio de un período en el que crecientemente tendrán concreción las demandas de reconocimiento de los gays. Veamos: los gays que hoy tienen 90 años tenían en aquel momento 58 años, los que hoy tienen 80 tenían 48, los que tienen 70 tenían 38 y así sucesivamente. ¿Quiénes, de quienes hoy son viejos o están en proceso de envejecimiento, han podido "desarrollar" más orgullo gay y representaciones de la vejez concomitantes? Obviamente que menos quienes tienen más edad y mucho más quienes tienen menos. Pero, justamente, uno de los puntos más interesantes para pensar hoy el envejecimiento gay está dado por la existencia de generaciones enteras que han quedado "en medio" del discurso alterizante y del discurso del orgullo. ¿Con cuál o con cuáles repertorios cognitivos significarán el envejecimiento?

"Polifasia cognitiva", la conocida formulación de Denise Jodelet (1986) hace referencia a esta situación perceptiva: el momento a veces largo en el que las representaciones se nutren de elementos provenientes de sistemas representacionales distintos. Categorizar entonces a los gays que hoy son viejos o están en proceso de envejecimiento como pertenecientes a generaciones "pre-Stonewall", "Stonewall" o "post-Stonewall" (Assis 
Simoes, 2004) (o como quiera denominarse estos períodos en cada país) es un atajo analítico a tener en cuenta ya que cada momento refiere a la pertenencia de los sujetos a uno o varios mundos socio-semánticos, asumiendo que la pertenencia a más de uno condiciona diferencialmente las probabilidades de la percepción.

A modo de ejemplo: una persona gay que vivió en Buenos Aires la reapertura democrática de 1983 y tenía 28 años en ese entonces, tiene hoy 60. Pensemos en esa persona e intentemos ver cómo podrían afectar su concepción del envejecimiento el conjunto de pliegues socio-semánticos que conforman su subjetividad. Por una parte, ha sido formado por el discurso alterizante y ha interaccionado en configuraciones sociales opresivas. Luego, fue inundado por la pérdida y el duelo y doblemente alterizado por la epidemia del SIDA en los años 80 y 90. ¿Qué perspectivas de futuro podía tener en aquel momento él y los de su generación? En particular: ¿qué perspectivas de envejecimiento? Con posterioridad, pudo apreciar cómo las organizaciones políticas gestionaban avances en los terrenos del estado y/o cómo en los medios masivos de comunicación se mostraba la cuestión gay con creciente respeto en ficciones e informes periodísticos y/o cómo se iban facilitando sus relaciones con su entorno no-gay, incluida su familia y/o como las Marchas del Orgullo iban sumando cada vez más gente (gay y no gay). Finalmente, hace 5 años fue testigo de lo inimaginable: la sanción de una ley de matrimonio civil, que le daría (a él y a los de su generación) la posibilidad de ser padres y con ello la posibilidad de experimentar uno de los marcadores del tiempo más característicos de sociedades como las nuestras que es, al mismo tiempo, un dador de sentido muy convencionalizado de la vejez puesto que habilita la posibilidad de la abuelidad. De todas estas posibilidades antes estaban privados. En este nuevo contexto: ¿Qué perspectivas de futuro se pueden tener? En particular: ¿qué perspectivas de envejecimiento? Y: ¿qué quedaría, remanente, de las perspectivas anteriores?

Esta persona de 28 años en el momento del "Stonewall argentino" tendría hoy (a los 60) más probabilidades que una persona que en ese momento tenía 38 (y hoy tiene 70) de representarse su envejecimiento desde el modelo perceptivo que comenzó a operar desde entonces. Si pensamos en gente de más edad esa probabilidad tendería a disminuir y si pensamos en gente de menor edad el modelo perceptivo tendería a tener operatividad preeminente. 


\section{Ernesto Meccia-Cómo los Gays Ven el Envejecimiento Gay}

Lo que estaría en juego, entonces, para representarse el envejecimiento entre quienes no son tan viejos ni son jóvenes sería su capacidad de "resiliencia" o su aptitud para volver inoperativas en el nivel cognitivo a las viejas imágenes degradantes de la homosexualidad y del envejecimiento homosexual.

Las teorías que expondremos a continuación, en su conjunto, parecieran estar abocadas a dar algunas respuestas a este inmenso interrogante. Todas basadas en investigaciones empíricas, veremos como algunas sostienen que la "buena vejez" en gays no sólo es posible sino exitosa, mientras que otras ponen esa capacidad seriamente en duda.

Una aclaración: por supuesto que no despegamos el análisis del envejecimiento gay del análisis que pudiera hacerse del envejecimiento de cualquier otra persona. No dudamos que existen procesos estructurales de minusvaloración social que son transversales en entramados sociales que, al decir de Marta Nussbaum (2006), hace que las personas sientan vergüenza de los signos de su humanidad, entre ellos, el "crepúsculo" de los cuerpos. Con todo, estamos convencidos de que existen torsiones particulares en este proceso que son imputables a la pertenencia de los sujetos de nuestra reflexión a una categoría social estigmatizada. No buscar en una investigación sociológica esa particularidad sería aportarle, imperdonablemente, a la cruenta maquinaria de su invisibilización social.

\section{Teorías de la Competencia en Crisis, Ajuste y Resiliencia}

En el contexto académico estadounidense, en los años 70, ya se disponía de agudas reflexiones sobre el envejecimiento que se esforzaban por desarmar el estereotipo de que el viejo gay representaba la alteridad absoluta y alicaída de sus pares heterosexuales, tenidos como los paladines de la buena vejez. Jim Kelly (1977) y especialmente Douglas C. Kimmel $(1978,1979)$ fueron los representantes de esta corriente: "La amplia diversidad de patrones de envejecimiento, la presencia de aspectos positivos del envejecimiento gay, y la alta satisfacción con la vida de muchos de los encuestados contradice el estereotipo del hombre gay aislado, solo, viejo." (1979: 239). Estas aproximaciones no postulan solamente que los varones heterosexuales no eran fuente de referencia legítima sino que se ven inmersos en un proceso de 
envejecimiento que, en comparación con el de los gays, es vivido traumáticamente.

Basado en un conjunto de entrevistas en profundidad, Kimmel elaboró un inédito argumento que denominó "competencia en crisis". Para el autor, los varones homosexuales de aquellos momentos, desde su nacimiento se habían visto obligados a lidiar con distintas fuentes de rechazo social: desde la familiar, pasando por la escolar y la laboral, entre otras. Este extendido rechazo hizo de ellos expertos precoces en manejos de crisis, sabios para gestionar la adversidad, campeones en el desarrollo de saberes y estrategias situacionales para salir airosos cuando todo el mundo quería aplastarlos. Y muchas veces lo habían logrado, lo cual sería una instructiva forma de corroborar la sabiduría del aserto "aquello que no te mata, te fortalece". Con estos antecedentes, sostiene, la vejez no tiene grandes chances de representar ninguna instancia particularmente dramática ya que los gays estarían preparados para hacerle frente. Bajo esta perspectiva, una crisis más casi no sería una crisis: si siempre que se los indujo a pensar lo peor de sí mismos supieron preservarse y si siempre que tuvieron problemas interaccionales supieron resolverlos, la etapa de la vejez no podría evocar la imagen de una espina. Así, la adversidad y el sufrimiento tempranos serían las grandes escuelas que proveerían a los gays de insumos para llevar adelante una vejez satisfactoria. Si existe un alto grado de resiliencia el mismo guardaría una relación de proporciones con la cantidad de crisis previamente superadas. Leemos en Kimmel (1979, p. 244):

Los entrevistados señalaron muchas de las ventajas, y las desventajas-, del envejecimiento como homosexual. Tal vez uno de los entrevistados resumió la ventaja de ser gay en proceso de envejecimiento con mayor claridad: 'La preparación para la vejez es mucho mejor entre los gays que entre los heterosexuales. Debido a que siempre ha sido así, no has esperado a nadie para cuidar de ti, salvo a ti mismo.' (...). Se continúa en gran parte realizando lo que antes se hacía para la gente gay, por lo que hay menos necesidad de adaptarse a nuevos roles y expectativas. Otro encuestado señaló que vivir solo durante los últimos años no es algo que caracterice solamente a la gente gay: muchos heterosexuales viven solos después de la muerte de su cónyuge, pero muchas personas homosexuales han vivido solos durante períodos considerables de sus vidas y están acostumbrados a ello. 


\section{Ernesto Meccia - Cómo los Gays Ven el Envejecimiento Gay}

Es interesante ver que los otros significativos son los propios homosexuales y cómo en esta subjetividad desempeñan un papel absolutamente positivo: son ellos (no los heterosexuales) una buena guía para una buena vejez. El experto en crisis no tiene que aprender en la vejez a vivir solo, ni a cocinar, ni a lidiar con las cuestiones del hogar. Ya hizo todo eso (y mucho más). Y allí se lo tiene: íntegro, siempre restablecido, ajustado más que satisfactoriamente a esta etapa. Un cierto halo de heroicidad y de plena reivindicación de la homosexualidad como escuela frente a la adversidad emerge de algunos testimonios, por ejemplo:

'Ser gay me dio todo lo que tengo intelectualmente, emocionalmente, todos los sentidos. Siento que ser gay es prácticamente un boleto para cruzar todo tipo de barreras sociales que nunca habría podido cruzar de otra manera', entre ellas: la vejez. (Kimmel, 1979, p. 244).

Entonces, y a contrapelo de los estereotipos de sentido común y de otras aproximaciones científicas, se tendría que la homosexualidad per se no es un factor de mal envejecimiento. Es claro que los entrevistados han señalado a Kimmel una serie de desventajas de la vejez pero las mismas no son imputables a la homosexualidad: los problemas de salud, y/o los ingresos monetarios insuficientes, y/o la depresión por la jubilación y por la pérdida del capital social, son cuestiones atinentes a cientos de millones de personas en situación de envejecimiento en las sociedades occidentales, comprendidas en las generales de una ley de paulatina desafiliación social.

La audaz teoría de la competencia en crisis (recordemos que las publicaciones de Kimmel son anteriores a la década del 80) fue y es utilizada como sólido antecedente en investigaciones que siguen destacando altas capacidades de resiliencia y ajuste en el envejecimiento no solamente de gays sino también de lesbianas.

Por ejemplo, Brown, Alley, Sarosy, Quarto y Cook (2001) presentaron los resultados de un estudio etnográfico en el que participaron un total de 69 gays de entre 36 y 79 años (la mayoría tenía entre 50 y 65). El objetivo era examinar cómo los hombres gay mayores ajustaron, psicológica y socialmente, la orientación sexual con el proceso de envejecimiento. Presentan algunos hallazgos interesantes. Por ejemplo: que los entrevistados pasan mucho tiempo en compañía de amigos gays dentro de sus propios 
grupos de edad. La mayoría informó estar involucrados con la comunidad gay habiendo participado o participando en alguna actividad, mientras que alrededor del $15 \%$ no tuvo participación alguna. De importancia: la mayoría de los participantes estaba en contacto regular con sus familias y afirmaron que las habían puesto al tanto de su orientación sexual. Por último, la mayoría dijo haber experimentado discriminación por su orientación sexual, y un tercio haber sufrido discriminación dentro de la comunidad gay por razones de edad o etnia. (Brown et al., 2001).

Comparado con Kimmel, los hallazgos siguen la misma dirección: cuestionar firmemente el estereotipo del homosexual mayor decadente, aislado, deprimido, retraído e inactivo. También exhorta a que no se confundan los planos de análisis: los gays mayores pueden tener problemas pero no por la orientación sexual sino como consecuencia de la estigmatización social. Tal vez hoy este razonamiento suene redundante pero no debemos olvidar que la literatura científica y de la divulgación de aquel entonces enmarcaba per se a la homosexualidad en el terreno patológico. De hecho, la desclasificación dentro del Manual de Desórdenes Mentales data de 1973.

Como añadido, este estudio enfatiza la variable "capital social" que parecería jugar un papel importante para la resiliencia, la recuperación y el mantenimiento de la alta estima de sí en la adultez y la ancianidad. Notemos que el capital social tiene dos indicadores: los amigos y, sobre todo, la "comunidad gay" la cual no solamente se reconoce sino que se visualiza como un lugar donde desarrollar actividades. Las conclusiones de los autores son óptimas, tal vez por demás:

El envejecimiento de los varones homosexuales tiene las mismas cuestiones que el de otros hombres de edad avanzada, aunque también se enfrentan a desafíos únicos y adaptaciones en sus vidas diarias. En general, los entrevistados en estos estudios se presentaron como ajustados social y psicológicamente en el proceso del envejecimiento. Ellos viven sus vidas como lo desean. Son activos en la comunidad gay. Son sexualmente activos. Mantienen relaciones amorosas estables y tienen vida social. Que ellos estén tan bien adaptados es un testimonio de su fortaleza. (...) Los estudios presentados aquí dan fuerte apoyo a los hallazgos anteriores que, en general, afirmaban que los hombres gay se adaptan bien al envejecimiento. (...). Tal vez, en 


\section{Ernesto Meccia - Cómo los Gays Ven el Envejecimiento Gay}

este momento, podemos decir con cierta convicción de que los hombres gay envejecen considerablemente bien y son relativamente libres de muchas de las complicaciones experimentadas por los varones heterosexuales de su misma edad (Brown et al., 2001, pp. 5253).

La teoría de la competencia en crisis y los enfoques del ajuste y resiliencia aciertan al lograr mostrar el otro lado de la moneda: allí donde el sentido común y gran parte de la producción científica mostraban decadencia y malestar se comenzó a mostrar envejecimientos alternativos con todo lo que ello supuso de visibilización para una categoría social que era furiosamente hablada por discursos homofóbicos. Sin embargo, en su afán de visibilización alternativa da la sensación de que estas teorías, llegado un momento, también pueden crear nuevas formas de invisibilización de realidades específicas del envejecimiento gay. Al respecto, existe evidencia empírica que haría insostenible una representación del envejecimiento tan extraordinaria.

Por ejemplo, los datos que presenta el gerontólogo Brian De Vries (2009), nos llevan a interrogarnos si la competencia en crisis no culminaría cuando los gays que envejecen se enfrentan a entornos médicos y de cuidados de salud en general. Veamos: en un estudio, el $18 \%$ de los gays manifestaron una valoración negativa de los servicios de salud puesto que sus efectores son insensibles frente a la orientación sexual. En tanto que un $25 \%$ de los gays dijeron que directamente no les manifestaron su condición sexual o raramente hablaron de ella. Aún personas gays mayores que lograron hacer el coming out frente a sus familias (uno de los indicadores de competencia para una buena vejez) parecieran encontrar un límite cuando se hallan expuestos ante la mirada médica, frente a la que quedarían paralizados, retrocediendo y volviendo a hacer el (antiguo) coming in. ${ }^{4}$ Las reacciones tendrían una preocupante razón de ser: De Vries (2009) cita un estudio de la Gay and Lesbian Medical Association de 2006 que revela que el $40 \%$ de los estudiantes de enfermería piensa que la orientación sexual es una cuestión de la esfera privada. En tanto que entre el 5 y el $12 \%$ encontraban que las personas LGTB eran "asquerosas" ("disgusting"). En la misma línea, otro estudio (realizado por MetLife, 2006) sostiene que el 19\% de los encuestados manifestaron tener poca o ninguna confianza en que el 
personal médico les otorgue un trato digno y con respeto en tanto personas LGBT en la vejez.

Como última reflexión: habría que tomar recaudos para que las investigaciones delimitaran las áreas de la vida social en las que estos gays se han movido competentemente $y$, sobre todo, para que mostraran aquellas en las que ello no ocurre ya que seguirían operativos mecanismos de percepción homofóbicos que producirían en los gays viejos más que competencia para enfrentarlos, competencia para evitarlos.

\section{Teoría del Envejecimiento Acelerado}

Según el antropólogo brasileño Julio Assis Simoes (2004), la primera formulación de este enfoque aparece en la obra de John H. Gagnon y William Simon (1973) y es retomada por Richard Friend (1980). La teoría de envejecimiento acelerado sostiene que los varones gays se ven a sí mismos como con más edad en un momento de la vida en el que los varones heterosexuales no se ven así.

No se trata solamente de una percepción académica. En la etnografía de Néstor Perlongher (1993) sobre el mundo de la prostitución masculina en San Pablo (Brasil) se puede apreciar como en el argot del lugar tenía cabida esta categorización etaria: entraban en la categoría de "tía" o "maricón" los homosexuales clientes que tenían 35 años y más. En Argentina, durante los años 80 y 90 en contextos de no prostitución la categoría también aludía a gente de la misma edad. Inclusive en el sentido del humor de las comunidades gays, la cuestión de la precocidad etaria es insistentemente traída con metáforas del mundo del espectáculo: gays de este rango etario que para hablar de sí mismos apelan a historias de divas que supieron retirarse a tiempo de la exposición pública para que no se vea el paso del tiempo. "El tiempo es cruel: destruye las ilusiones y muestra las arrugas" le dicen en los años 40 a una diva del cine argentino (primer ícono homosexual) advirtiéndola para que deje a su amante mucho más joven. ${ }^{5}$ Asimismo esta estratificación llega a la actualidad: en los sitios web pornográficos gays la etiqueta "mature" trae imágenes de actores de esa edad. Por último, presentamos una anécdota del gerontólogo Richard Friend (1980). Cuenta que para realizar una investigación publicó un aviso clasificado en distintos medios comunitarios gays. Buscaba varones 


\section{Ernesto Meccia - Cómo los Gays Ven el Envejecimiento Gay}

homosexuales de los "más viejos" que le concediesen entrevistas. Se sorprendió de haber recibido un número importante de respuestas por parte de personas que estaban entre los 30 y los 40 años.

Estimo que no es ésta la ocasión para cotejar si esta lectura del paso del tiempo es tan distinta de la que realizan varones y mujeres heterosexuales de la misma edad. Tampoco lo expresado debería servir para afirmar que los gays tienen una lectura "errada" de la realidad. Al contrario, habría que intentar hacer inteligible desde adentro las cosas y eso haría trizas las nociones de lo verdadero y lo falso, erigiendo exclusivamente lo que es "evidente" en ámbitos finitos de sentido (Schutz, 1974; Schutz y Luckmann, 1977).

Robert Schope, un investigador que retoma algunos planteos de la teoría del envejecimiento acelerado, aporta una sugestiva reflexión cuando dice:

...esto se hace eco de la opinión comúnmente aceptada que un hombre gay es viejo cuando cumple 30 años (Berger, 1982b). Los hombres gay que salen de los últimos veinte años o que transitan sus treinta años pueden incluso sentir que han saltado desde la adolescencia a la edad madura o vieja. Los hombres gay pueden interpretar envejecimiento en forma "inapropiada" porque carecen de los "marcadores" sociales que guían la percepción del tiempo de los heterosexuales (Schope, 2005, p. 25).

Se trata de una reflexión, en mi opinión, no exenta de dramatismo, sobre la que presentaré dos reflexiones. Primera: más arriba nos habíamos referido al período pre-Stonewall en términos de la existencia de discursos cruentamente alterizantes y de configuraciones societales y jurídicas adversas hacia los gays. Era tal el nivel de represión de la homosexualidad que muchos gays directamente se retiraban o no se involucraban en diversas oportunidades interaccionales bajo la justificación "esto no es para nosotros" (Bourdieu, 1988) debido al miedo a ser descubiertos y ser objeto del descrédito. Ante semejantes retiradas de la vida social es adecuado plantear que bien podrían sentir que se encontraban fuera de la historia o que la historia era algo que les pasaba a los otros, es decir, a los heterosexuales. Si imaginariamente un almanaque funcionaba, ése era el de la sociedad heterosexual, esa entidad tan tremenda que cotidianamente los colocaba en sus márgenes. Por lo tanto, tiene sentido postular que estarían echadas las 
cartas para una percepción diferencial del tiempo y del transcurrir, justamente porque el transcurrir era el de los demás y la vida era una especie de espectáculo obligado para los homosexuales.

Los ritos de pasaje que vivenciaban los heterosexuales, como los de convertirse en padres, festejar la graduación de los hijos o, finalmente, ser abuelos, no eran vivencias de los homosexuales en aquellos contextos sociales y jurídicos. Aunque esto no ha sido estudiado, es muy probable que se encuentre allí parte importante de la clave de esta alteración de la temporalidad: los gays habrían vivenciado las mismas etapas que los heterosexuales pero sólo hasta la adolescencia, el momento del descubrimiento sexual y, en consecuencia, del subsiguiente ocultamiento y de la retirada de la corriente de las vivencias socialmente pautadas, las vivencias, dijimos, de quienes quedaban "adentro" de la historia. En estas condiciones, "jóvenes" solamente podrían ser los heterosexuales porque solamente ellos cumplían dentro de la "juventud" con ritos convencionalizados como noviar, casarse y tener hijos. En cambio, los gays, privados de estas posibilidades, "saltaban" directamente desde la adolescencia a la "madurez". El envejecimiento, en consecuencia, les quedaba mucho más cerca.

Segunda reflexión: Además, ¿cómo no ponderar en este "gran” salto adelante la influencia del sentimiento de pérdida y duelo de la época del SIDA? En esa tremenda coyuntura también los gays (y sólo los gays) tuvieron que hacerse grandes aceleradamente, crecer de golpe, experimentando en plena juventud gigantescas pérdidas afectivas, esas pérdidas que sus pares heterosexuales muy por lo general experimentarían en su vejez. Otra vez, aquí tenemos otro proceso dramático que llevaría a estas personas rápidamente hacia la vivencia de eventos propios de otra etapa de la vida. ¿Cómo, bajo estas condiciones, no sentirse maduro antes de tiempo?

Si la comparamos con la teoría de la competencia en crisis, ajuste y resiliencia, la teoría del envejecimiento acelerado presentaría un perfil representacional menos dinámico. Si en aquella el curso de la vida, incluido el envejecimiento, se aparecía ante los gays como un conjunto de oportunidades para salir adelante, ajustándose exitosamente y teniendo a los gays como otros significativos positivos, en la teoría del envejecimiento acelerado tendríamos que la lectura del envejecimiento estaría fatalmente teñida por representaciones que fueron provistas por vivencias pasadas negativas de la 


\section{Ernesto Meccia-Cómo los Gays Ven el Envejecimiento Gay}

homosexualidad. Vimos como la precocidad de la imaginación era la otra cara de la moneda de ver que los heterosexuales, a diferencia de ellos, tenían una historia porque estaban en la historia, es decir, tenían una vida con etapas que se desarrollaba paulatinamente. Entonces, podría postularse que esta subjetividad postularía como otros significativos a los pares etarios heterosexuales respecto de los cuales se mediría y evaluaría negativamente al no haber "vivido lo suficiente".

Pero esta subjetividad no solamente pondría como otros significativos a los heterosexuales; también el sentimiento de precocidad etaria se daría porque se pone en escena a la sociedad gay. Sí: los gays mayores sienten que "desde adentro" se los induce a pensarse negativamente. El peso de la "sociedad gay" sobre su autopercepción es notoriamente gravoso, algo que no sucedería así en el caso de las lesbianas que envejecen en relación con la "sociedad lesbiana", aparentemente mucho más tolerante del envejecimiento.

Robert Schope (2005) dirigió una encuesta administrada a 183 personas, 74 de las cuales eran gays y 109 lesbianas. Se crearon dos grupos de edad: 105 encuestados de menos de 40 años (52 gays y 53 lesbianas) y 78 encuestados de 40 y más (22 gays y 56 lesbianas). Los porcentajes de las respuestas a cómo ambas sociedades veían la vejez muestran una importante diferencia en la percepción de la edad según los respondentes sean gays o lesbianas, delineándose una tendencia que opaca la edad de los mismos como variable explicativa. Esto es: que más allá de la edad que tengan los gays y las lesbianas, existiría un patrón perceptivo amigable con el envejecimiento lesbiano por parte de las lesbianas y un patrón perceptivo adverso en el caso de los gays. Presentamos algunos resultados:

a) El 50\% de la muestra de varones gays jóvenes opina que la visión de la sociedad gay sobre la vejez gay es "terrible" y el 38.5\% que es "tolerable"; en tanto que los gays mayores, aunque pudieran sentirse bien con su vejez personal, piensan en un $36.4 \%$ que la visión es "terrible" y otro $36.4 \%$ que es "tolerable". Es decir que el $88.5 \%$ de los gays jóvenes han elegido las categorías "terrible" o "tolerable" para significar cómo los gays ven el envejecimiento, en tanto que han elegido lo mismo el $72.8 \%$ de los que tienen más de 40 años. El 37.3\% de las lesbianas más jóvenes, en cambio, eligió la categoría "aceptable" y un 27.5\% la categoría "buena" para significar cómo la sociedad lesbiana ve el envejecimiento lesbiano, en tanto 
que las que tienen más de 40 años eligieron la primera categoría en un $36.5 \%$ y la segunda en un $32.7 \%$. Sumado, tenemos que el $64.8 \%$ de las lesbianas jóvenes sienten que la sociedad lesbiana evalúa "aceptablemente" o "bien" el envejecimiento lesbiano, en tanto que las más grandes ven lo mismo en un $69.2 \%$.

b) Preguntados sobre cómo ven su propio envejecimiento, los porcentajes varían aunque la tendencia (cierto que mucho más reducida) seguiría teniendo vigencia: el $28 \%$ de los gays más jóvenes sienten "tolerable" su propio envejecimiento, junto a un $27.3 \%$ entre los gays más grandes. Pero al mismo tiempo, el $34,6 \%$ de los primeros lo ven "bien" y un $31.8 \%$ de los segundos también. Respecto de las lesbianas el $11.3 \%$ de las más jóvenes ven con "tolerancia" el proceso junto al $10.9 \%$ de las más grandes, en tanto que han elegido la categoría "buena" un $30.2 \%$ y un $15.5 \%$ respectivamente y la categoría "fantástica" un $24.5 \%$ y un $12.7 \%$ (contra un $3.8 \%$ y un $9.1 \%$ de los gays).

c) En términos generales, o mejor, en la "superficie", existiría una considerable aceptación personal de la propia vejez en el caso de los gays especialmente si se compara ese cuadro con el cuadro de cómo la sociedad gay ve el proceso. Sin embargo, la capacidad de recuperación de esas imágenes sociales no sería significativa ya que,

d) los varones gays estiman que son "old" a una edad promedio de 39 años, en tanto que las lesbianas sienten lo propio a los 49 años, 10 años después.

Sin duda que los datos de Schope son sugerentes aunque por momentos no resultan precisos ya que no se sabe si la principal variable que explica el sentimiento de envejecimiento acelerado en gays mayores es el "género" o la "orientación sexual". También estimamos que lo que presenta es un conjunto de variaciones concomitantes que permiten ver cómo ciertos valores de una variable corren junto con los de otra pero no muestra "por qué" corren juntos. Además, el único factor que presenta resulta insuficiente: habla de las particularidades de la socialización gay que, a diferencia de la de las lesbianas, tendría epicentro en una red de bares donde tendría que mostrarse una apariencia física óptima; algo que resultaría una postal del pasado que ha sido superada, en parte, por la socialización a través de Internet. Sea como sea, sigue pareciendo una explicación atractiva pero incompleta; y ello no representaría necesariamente un déficit del autor: antes bien, podría 


\section{Ernesto Meccia-Cómo los Gays Ven el Envejecimiento Gay}

representar uno de los tantos casos en que un fenómeno social muestra un desenvolvimiento muy difícil de seguir a través de estimaciones estadísticas, si es que de esa forma se lo puede efectivamente rastrear.

Ante este panorama nos parece pertinente reponer parte de la hipótesis que Martin Levine expuso en "Gay Macho" (1998). El sociólogo, al estudiar las transformaciones de las expresiones de género de la homosexualidad post-Stonewall, pudo detallar dos momentos de un proceso de transición. En el primer momento era predominante la asociación de la homosexualidad masculina a un alma femenina (la figura del "hombre fallido"); en el segundo momento (que es el momento post-Stonewall) surgiría una nueva figura en el imaginario social, la del gay masculinizado y vigorizado por la juventud, en un contexto de estrechamiento del ideal masculino. A través de un estudio etnográfico, Levine documentó cómo la transición imaginaria era asimismo discernible en las prácticas de socialización gays y concluyó que esa neo-masculinidad conjugaba la parodia y la emulación.

El estudio de Schope se publicó en 2005 y fue realizado en 2002. Vale decir que muchos de sus encuestados mayores se socializaron antes, durante y después de Stonewall, es decir, han andado la transición señalada por Levine. Con ello queremos sugerir que la variable género pudo haber operado en estas generaciones en el sentido de haberles solicitado más masculinidad y vigor juvenil, tal el "precio" de aquella primera visibilización gay. Los encuestados de Schope en aquel contexto tal vez hayan emulado más que parodiado la masculinidad hegemónica. Nuestra hipótesis es que lo expuesto nos da buenas razones para suponer que, si repitiéramos la encuesta de Schope en el día de hoy, la percepción del envejecimiento gay acelerado no tendría esos ribetes dramáticos, probablemente porque los jóvenes gays de hoy hacen más parodia que emulación de la masculinidad recia y juvenil; y a más "distancia de rol" (Goffman, 1974) más probabilidad de que el envejecimiento gay se representa a través de otro esquema.

\section{Teoría del Estrés de Minorías}

Ilan Meyer (2003, 2011) es un psiquiatra interesado en las políticas públicas destinadas a las poblaciones LGTB. Sus investigaciones ponen un énfasis especial en las condiciones sociales que pueden afectar la salud mental. Es 
autor de la teoría del "estrés de minorías" en la que conjuga elementos conceptuales de la psicología, la psicología social y la sociología que viene siendo aplicada en el estudio del estrés provocado por situaciones interaccionales violentas como, por ejemplo, el bullying. Estimamos que presenta varios puntos de interés para incorporarla al estudio del envejecimiento gay. Meyer se acerca a la definición de este fenómeno aludiendo metafóricamente al sobrepeso:

El estrés puede ser definido como cualquier condición que tiene el potencial de despertar la maquinaria adaptativa de una persona. Utilizando el análisis de la ingeniería, el estrés puede ser descripto como una carga respecto a una superficie de apoyo. Al igual que una superficie se puede romper cuando el peso excede su capacidad para soportar la carga, el estrés psicológico ha sido descripto como un punto de ruptura a partir del cual un organismo puede llegar al "agotamiento" (Meyer, 2001, p. 09).

Esta sucinta definición ya dejaría entrever más momentos de un proceso que no estaban presentes en la teoría de la competencia en crisis. Si este último pone el acento en la "competencia" ante la crisis, en Meyer pareciera que la competencia es una de las respuestas posibles de la maquinaria adaptativa de la persona inmersa en un contexto de discriminación. La otra respuesta de la maquinaria es, justamente, una "no respuesta" producto de la incapacidad de elaborarla. El estrés es ni más ni menos que el resultado de esa inoperatividad: el agotamiento ante una situación crítica que abruma la subjetividad de los sujetos porque no se acierta o no se avizora el modo de su resolución. La cadena causal sería: identidad sexual no heterosexual, situación interaccional adversa y violenta, búsqueda de respuesta, falta de respuesta, agobio, estrés, afectación de la salud mental (paradigmáticamente: aislamiento y depresión). Ya veremos que de una forma interesante Meyer sugiere de qué dependería, sociológicamente hablando, que las personas puedan gestionar satisfactoriamente la adversidad y lograr ajuste y resiliencia.

El estrés se produce por dos clases de factores. En primer lugar están los que denomina "estresores generales": el duelo ante la pérdida de seres queridos, situaciones de minusvaloración identitaria producto de situaciones crónicas como la falta de empleo o la aparición de una enfermedad 


\section{Ernesto Meccia-Cómo los Gays Ven el Envejecimiento Gay}

discapacitante o la dinámica misma de la vida en las grandes metrópolis son algunos ejemplos. La característica principal de estos estresores es que: "son ubicuos, todos los individuos en las sociedades modernas están expuestos a ellos" (Meyer, 2011, p. 10). En segundo lugar están los factores cuya capacidad de afectación es diferencial ya que logran abrumar a los integrantes de grupos minoritarios catalogados negativamente. Son los "estresores de minorías":

las personas de estatus sociales desfavorecidos están expuestos a factores de estrés añadidos, que son únicos. Me he referido a éstos como estrés (también social) de minoría. El estrés de la minoría proviene de la desventaja social relacionada con el estigma estructural, el prejuicio y la discriminación. (...). Por definición, el estrés minoría es único, ya que afecta y requiere adaptación especial por las personas LGB, pero no por los heterosexuales (Meyer, 2011, p. 10).

Por lo tanto tendríamos que los integrantes de minorías sociales negativamente etiquetadas tendrían que hacer frente a ambos tipos de factores, lo que produce una sobrecarga adaptativa.

Meyer ha descrito cuatro vías por las cuales los procesos de estigmatización se incorporan en la gente. Los presentaremos teniendo en cuenta las vicisitudes de los sujetos de nuestra reflexión. La estigmatización se hace carne en las víctimas: (a) a través de eventos originados en prejuicios y/o en condiciones prejuiciosas crónicas; por ejemplo, expulsión o marginación de los ámbitos educativos y miradas familiares tenidas como negativas aun cuando no se hayan concretado en ningún evento dramático, (b) a través de la auto vigilancia concomitante ante las expectativas negativas de los demás; por ejemplo, evitando a las personas cuya frecuentación, según ellos, puede confirmarlas, (c) a través de la internalización del estigma social ("homofobia internalizada", en nuestro caso), y (d) a través del ocultamiento de la identidad gay ante los auditorios no gays. Al respecto ya hemos visto el ejemplo del coming in en los escenarios médicos de los gays mayores, al que debemos agregar la no revelación de la identidad sexual a sus hijos por parte de gays mayores o viejos que son padres (Meyer, 2011).

Esta es una de las caras de la dinámica social de las minorías: la que se asocia al estrés irresuelto porque los otros significativos son representantes 
del heterosexismo que operan negativamente en la visión de sí. Pero para Meyer también se debería ver el reverso, explorando la idea de que pertenecer a una minoría puede tener un resultado positivo permitiendo resolver el estrés y volviendo a los gays mayores "competentes" para enfrentar lo que tengan que enfrentar, como quería Kimmel.

Estamos ante uno de los planteos más interesantes de la teoría del estrés de minorías. Meyer propone pensar la diferencia entre envejecer "individualmente" como gay y envejecer como "miembro" de la minoría gay; una distinción que trae a la polémica la cuestión del capital social de los sujetos discriminados. Puede suponerse que los homosexuales que envejecieron en ausencia de una plataforma cognitiva gay hayan envejecido en forma individual y en situaciones de estrés crónico, negándose a reconocer en los otros homosexuales a sus pares debido a la homofobia internalizada, la cual podía incrementarse debido a que la figura misma de la "vejez" era uno de los objetos permanentemente recreado por los discursos alterizantes. De modo inverso, es probable que los gays que envejecen en contextos contemporáneos y posteriores a Stonewall lo hayan podido hacer y lo hagan en compañía de la plataforma cognitiva "orgullosa".

Queremos sugerir que la sociabilidad gay mediada por las nuevas coordenadas cognitivas (amplificadas por los medios de comunicación) puede operar en la dirección de que los gays viejos o en proceso de envejecimiento se animen a compartir las vivencias de esta etapa de la vida y que ello redundaría en el resultado cognitivo mayor de lograr neutralizar a los otros significativos negativos poniendo en acción a los que envejecen con ellos y como ellos.

Pero esto plantea un gran interrogante que desplaza el análisis hacia dimensiones que no hemos tocado hasta el momento. Y sobre todo hacia una: ¿en dónde, en qué lugares estos gays podrán socializarse, encontrarse, reconocerse y desarrollar un sentimiento de pertenencia que neutralice los aspectos negativos? La pregunta es significativa ya que los gays mayores se retirarían de los circuitos de socialización con propósitos sexuales utilizados por los jóvenes (bares, saunas, discotecas), circuitos que ven con un importante sentimiento de exterioridad y ajenidad, a lo cual habría que sumar la sensación de extrañeza derivada de la denominada "brecha digital". ${ }^{6}$ 


\section{Ernesto Meccia-Cómo los Gays Ven el Envejecimiento Gay}

La falta de "lugar" en un sentido genérico es uno de los temas emergentes más importantes de los testimonios que obtuve para mis investigaciones:

¿Dónde se van los gays que ya no están? ¿Qué pasa que ya no los veo, que hace rato ya no están? ¿Dónde se habrán metido? ...porque no circulan más? (...) ¿Se desvanecieron? ¿Se fueron a Europa? ¿Se murieron? (...). Me gustaría en un futuro no muy lejano, ser el mentor y generar un espacio alternativo para gays adultos mayores, donde puedan tener la contención adecuada a sus necesidades específicas, y porque considero que una sociedad sana es aquella que también tiene en cuenta a sus mayores (Raúl, 72 años).

Y yo le preguntaba: ¿no se piensa en algún lugar para gente de nuestra edad? Porque hay mucha gente sola. Yo veo mucha gente grande, sola, que no tiene familia y yo podría compartir con otro. O sea, la idea era que, cuando éramos jóvenes y llegáramos a esta edad dijéramos: “¿qué tenés vos? ¿y qué tenés vos?" Bueno, entonces compramos, por ejemplo, una casa con ocho habitaciones. Vamos a compartir, vamos a convivir. Tenemos gente que nos limpie, tenemos gente que nos cocine. O sea: tener una vejez digna. Ayudarnos. Que no se nos vaya nada a la cabeza. $O$ sea, vos ves hoy un tipo gay grande, de nuestra edad y vos ves que está lleno de ganas de hablar porque está solo, no está en pareja. "La casa comunitaria", te cierro así la idea. No sé quién se podría encargar es esto pero es necesario y porque es muy interesante. Pero, no sé, los chicos de hoy en día no apuestan, pican, y además no tienen un sentido profundo de lo que es la amistad (Rafael, 57 años).

No encuentro ni a mis amigos o conocidos (algunos lógicamente fallecieron) pero si los encuentro advierto que se les ha terminado la cuerda, son como relojitos de aguja que dejaron de funcionar. Qué se yo. Podés preguntarte: “¿adónde estarán?” pero hay respuestas que a veces te duelen. Lo que te quiero decir, es que para mi generación fue una cuestión muy difícil aceptarse a uno mismo. Y tengo la teoría que si no te aceptas te borrás del mundo. ¿Y cómo no te vas a borrar más si además sos un viejo y no tenés adónde ir? Pasa una cosa curiosa: en "El Olmo"7 hasta hace un tiempo iba mucha gente de mi edad. Ahora... ni eso. Esto es un misterio en apariencia porque, ya te dije, la 
gente se borró porque siente que ni se aceptan ni los aceptan (Juan Carlos P., 74 años).

Para mí la utopía gay es eso que te dije: que haya espacios, que se creen lugares de socialización donde no solamente te alaben por lo fálico, y eso que a mí me alaban por eso, pero claro... no soy solamente eso (Carlos, 67 años).

Como vemos, el encuentro de una casa bajo el arcoíris o la edificación de un hogar al final del camino aparecen como anhelo, necesidad, como una utopía para los gays viejos o en proceso de envejecimiento. En su conjunto estos testimonios parecieran reclamar un entramado institucional que aún no existe ni como "forma social pura" ni como parte de la agenda de un programa integral de política pública destinada a la vejez LGTB. Y esa ausencia limitaría poner a favor del envejecimiento gay la pertenencia minoritaria en el sentido en que lo planteaba Meyer.

\section{Una Polémica Sociológica}

Respaldados en investigaciones empíricas, hemos tratado de suministrar a los lectores una polémica sociológica en torno a las representaciones sobre el envejecimiento gay que tienen los gays en la actualidad. Sostuvimos que esas representaciones no vienen a cuenta de ninguna realidad en el sentido de que no existirían unas más verificables que otras. Hablar de representaciones sociales de la vejez, dijimos, conduce la investigación a detectar cuáles son los atributos del "modelo perceptivo" que sostienen y, en particular, qué papel se asigna a los otros significativos. Los tres enfoques que presentamos son de gran interés para armar y para seguir con esta polémica cuya pertinencia, sin embargo, muy probablemente sea exclusiva de las "generaciones bisagra" que hemos analizado, cuya subjetividad está compuesta por la mezcla del discurso alterizante y el discurso del gay pride.

Por supuesto que nada garantiza el "avance" en la historia de los grupos discriminados; pero es más que probable que esta polémica no demuestre el mismo potencial cuando, en el futuro, se investigue el envejecimiento de los gays de las últimas generaciones. Sin duda que otros modelos perceptivos cobrarán vigencia. 


\section{Ernesto Meccia-Cómo los Gays Ven el Envejecimiento Gay}

Cuadro resumen (elaboración propia):

\begin{tabular}{|c|c|c|}
\hline & $\begin{array}{c}\text { OTROS } \\
\text { SIGNIFICATIVOS }\end{array}$ & $\begin{array}{c}\text { LOGRO DE } \\
\text { RESILIENCIA }\end{array}$ \\
\hline $\begin{array}{c}\text { COMPETENCIA EN } \\
\text { CRISIS }\end{array}$ & Gays & Positivo \\
\hline $\begin{array}{c}\text { ENVEJECIMIENTO } \\
\text { ACELERADO }\end{array}$ & Heterosexuales & Negativo \\
\cline { 2 - 3 } & Gays & Negativo \\
\hline $\begin{array}{c}\text { ESTRÉS DE } \\
\text { MINORÍAS }\end{array}$ & Heterosexuales & Negativo \\
\cline { 2 - 3 } & Gays & Positivo \\
\hline
\end{tabular}

\section{Notas}

1 Por ejemplo, el viejo gay aparece como "amenazante" en una escena de "pánico homosexual" en I Vitelloni (Federico Fellini, 1953) y como "decadente" en Morte a Venezia (Luchino Visconti, 1971).

${ }^{2}$ En Begginers (Mike Mills, 2010) hay una historia de coming out orgulloso de un gay anciano que forja así un gran vínculo con su hijo. En Gerontophilia (Bruce LaBruce, 2013) se tiene la reivindicación de la belleza de un anciano gay por parte de un joven. En Love is Strange (Ira Sachs, 2014) se cuenta desde una perspectiva nativa los avatares de una pareja gay en proceso de envejecimiento. Se trata de películas incomparables por la construcción de una imagen positiva y desdramatizadora. 
${ }^{3}$ Esta periodización se encuentra desarrollada en un interesante artículo del antropólogo Julio Assis Simmoes referido a las antiguas y nuevas convenciones sobre la periodización de la vida de los gays en Brasil.

4 “Coming in": utilizo esta expresión respetando la definición que me diera un entrevistado en el curso de mis investigaciones. "Saliendo un poco de los vapores de nostalgias y melancolías, me he dado cuenta que en el llamado "estilo de vida gay" hay un período del "coming out" (pasar afuera $=$ salir $=$ exponerse) que también puede ser seguido de otro periodo, no demasiado investigado que por ahora bautizaré, por juego idiomático, como el "coming in" (pasar adentro = entrar = ocultarse)" (Raúl, 72 años).

5 La película se llama "El canto del cisne" (Carlos Hugo Christensen, 1945). Su protagonista fue Mecha Ortiz, femme fatal por excelencia de los años 40, apreciada por viejas generaciones de homosexuales en Argentina. En sus papeles más famosos era amante de varones muy jóvenes y el tema del envejecimiento y la "consecuente" discordancia no tardaba en aparecer dramáticamente.

${ }^{6}$ Debe reconocerse, no obstante que, por ejemplo, en la ciudad de Buenos Aires funcionan algunos establecimientos de este tipo donde la concurrencia gays mayores y ancianos es notoria.

7 "El Olmo" es una confitería que durante los años 80 y hasta fin del siglo XX fue un punto de encuentro importante de los gays. Sito en la intersección de las avenidas Santa Fe y Pueyrredón de la ciudad de Buenos Aires, particularmente los sábados por la noche se veía súbitamente híper poblada por gays de la ciudad y sus adyacencias.

\section{Referencias}

Assis Simoes, J. (2004). Homossexualidade Masculina e Curso da Vida: pensando idades e identidades sexuais. En Carrara, Sergio, Gregori, María Filomena y Piscitelli, Adriana (orgs), Sexualidade e Saberes: Convenções e Fronteiras (pp. 415-447). Rio de Janeiro: Garamond. Becker, H. (2009). Outsiders. Hacia una sociología de la desviación. Buenos Aires: Siglo XXI.

Bourdieu, P. (1988). La distinción. Criterios y bases sociales del gusto. Madrid: Taurus.

Bourdieu, P. (2007). El sentido práctico. Buenos Aires: Siglo XXI. Brown, L., Alley, G., Sarosy, S., Quarto, G. y Cook, T. (2001). Gay Men: Aging Well! Journal of Gay and Lesbian Social Services, 13(4), 41-54. Doi: 10.1300/J041v13n04_06 
94 Ernesto Meccia-Cómo los Gays Ven el Envejecimiento Gay

De Vries, Brian (2009). Aspects of Death, Grief, and Loss in Lesbian, Gay, Bisexual and Transgender Communities. En Doka, K. J. y Tucci, A. S. (eds), Living with Grief: Diversity and End-of-Life Care (pp. 243-257). Washington, DC: Hospice Foundation of America.

Friend, R. (1980). Gay Aging: Adjustment and the Older Gay Male.

Alternative Lifestyle, 3(2), 231-248. Doi: 10.1007/BF01083517

Gagnon, J. y Simon, W. (1973). Sexual Conduct: the Social Source of

Human Sexuality. Chicago: Aldine.

Goffman, E. (1974). La presentación de la persona en la vida cotidiana.

Buenos Aires: Amorrortu.

Goffman, E. (2006). Frame Analysis. Los marcos de la experiencia. Madrid:

Centro de Investigaciones Sociológicas.

Jodelet, D. (1986). La representación social: fenómeno, concepto y teoría.

En Moscivici, Serge, Psicología Social (II) (pp. 469-493). Barcelona:

Paidós.

Kelly, J. (1977). The Aging Male Homosexual. Myth and Reality. The

Gerontologist 17(4), 328-332. Doi: 10.1093/geront/17.4.328

Kimmel, D. (1978). Adult Development and Aging: a Gay Perspective.

Journal of Social Issues 34(3), 113-130. Doi: 10.1111/j.1540-

4560.1978.tb02618.x

Kimmel, D. (1979). Life-Story Interviews of Aging Gay Men. International Journal of Aging and Human Development 10(3), 239-248. Doi:

10.2190/LEU6-479Y-92ED-84GM

Levine, M. (1988). Gay Macho. The Life and Death of the Homosexual

Clone. New York: New York University Press.

Mead, G. (1972). Espíritu, persona y sociedad. Desde el punto de vista del conductismo social. Buenos Aires: Paidós.

Meccia, E. (2011). Los últimos homosexuales. Sociología de la homosexualidad y la gaycidad. Buenos Aires: Gran Aldea Editores

Meyer, I. (2003). Prejudice, Social Stress, and Mental Health in Lesbian, Gay, and Bisexual Populations: Conceptual Issues and Research Evidence. Psychological Bulletin, 129(5), 674-697. Doi: 10.1037/00332909.129.5.674

Meyer, I. (2011). Briefing on Peer-to-Peer Violence and Bullying: Examining the Federal Response. Washington: United States Commission on Civil Rights. 
Nussbaum, M. (2006). El ocultamiento de lo humano. Repugnancia, vergüenza, ley. Buenos Aires: Katz Editores.

Perlongher, N. (1993). La prostitución masculina. Buenos Aires, Ediciones de la Urraca.

Schope, R. (2005). Who's Afraid of Growing Old? Gay and Lesbian

Perceptions of Aging. Journal of Gerontological Social Work, 45(4), 2339. Doi: 10.1300/J083v45n04_03

Schutz, A. (1974). El problema de la realidad social. Buenos Aires: Amorrortu.

Schutz, A. y Luckmann, T. (1977). Las estructuras del mundo de la vida. Buenos Aires: Amorrortu.

Ernesto Meccia es Profesor Regular de Sociología en la Universidad Nacional del Litoral y en la Universidad de Buenos Aires (Argentina).

Contact Address: ernesto.meccia@gmail.com 